\title{
Postoperative Assessment of Gustatory Activity Following Surgical Removal of Mandibular Third Molars
}

\author{
Siddhartha Dhanda ${ }^{1}$, Soumi Samuel ${ }^{2}$ \\ 1,2 Department of Oral and Maxillofacial Surgery, AB Shetty Memorial Institute of Dental Sciences, \\ NITTE (Deemed to Be University), Deralakatte, Mangalore, Karnataka, India.
}

\section{ABSTRACT}

\section{BACKGROUND}

The study focused on prospectively determining the incidence and severity of taste changes after surgical removal of mandibular third molar and correlating difficulty index of impaction and incidence of gustatory changes.

\section{METHODS}

96 patients who required lower third molar extraction were included in the study. Their difficulty of impaction was measured using Pell and Gregory Difficulty Index and their gustatory activity was measured using a spatial taste test and a whole mouth wash test. The tests were carried out using 5 different stimuli, i.e., sweet, salt, bitter, umami and sour, in different concentrations and the subjects were asked to identify the stimuli preoperatively, postoperatively on day 7 and after 1 month. Tastes were scored from 1 - 9 for decreasing and altered taste sensations.

\section{RESULTS}

The results of our study showed that with increased difficulty index, taste sensation was altered. While most patients belonged to the Class II and Class I group as well as position $\mathrm{A}$ and $\mathrm{B}$, taste changes were still noted due to difficulty in impaction, especially in the patients belonging to Class III and position C groups. The taste changes felt at POD - 7 were similar and unresolved in the one month follow up. The scores had a statistically significant difference $(\mathrm{P}<0.05)$.

\section{CONCLUSIONS}

With a higher difficulty score, gustatory changes are felt due to the increased surgical manipulation required to remove the tooth from its socket. This is indicative of nerve damage during surgical extraction.
Corresponding Author: Dr. Soumi Samuel,

Department of Oral and Maxillofacial Surgery, AB Shetty Memorial Institute of Dental Sciences, Nitte University, Deralakatte, Mangalore, Karnataka, India. E-mail:soumisamuel@gmail.com

DOI: $10.14260 / j e m d s / 2021 / 312$

How to Cite This Article:

Dhanda S, Samuel S. Postoperative assessment of gustatory activity following surgical removal of mandibular third molars. J Evolution Med Dent Sci 2021;10(20):1489-1495, DOI: $10.14260 /$ jemds $/ 2021 / 312$

Submission 10-01-2021, Peer Review 17-03-2021, Acceptance 24-03-2021, Published 17-05-2021.

Copyright (C) 2021 Siddhartha Dhanda et al. This is an open access article distributed under Creative Commons Attribution License [Attribution 4.0 International (CC BY 4.0)]

\section{KEY WORDS}

Postoperative, Assessment, Gustatory, Mandibular, Third Molar 


\section{BACKGROUND}

The perception of taste gets activated when the taste receptor cells located on the taste buds react to a substance chemically. These receptors are mostly found on the tongue. ${ }^{1,2}$ Chorda tympani nerve is responsible for taste sensations of the tongue along with lingual nerve which joins with mandibular nerve as it exits the mandibular foramen.1,2,3,4,5 The chorda tympani nerve runs along the medial surface of the mandible in close proximity to third molar which puts it at a considerable risk to damage during surgical extraction.1,2,5,6 Taste chemoreception from anterior $2 / 3$ is carried out by chorda tympani nerve while lingual nerve is primarily somatosensory along with taste chemoreception. ${ }^{1,2,3,4}$ Nerve injury following disimpaction of third molar is one of the most frequently occurring complications and taste chemoreception and somatosensory perception are at risk during third molar extraction, which also depends on the degree of difficulty of the extraction. 4,6

Following disimpaction of the impacted mandibular third molar, dysesthesia is the most commonly observed complication. $6,7,8,9,10,11$ The incidence of complication of nerve injury can be reduced with appropriate preoperative evaluation and surgical precision.9,11,12,13 It's considered that the surgical procedure causes the nerve damage, but in some of the cases administration of local anaesthetics via blocking the inferior alveolar nerve is also considered to cause injury to the nerve. $9,11,14$ Subjects were noted to have good prognosis after dental injection regardless of nerve injury, whether they had the presence or absence of sensation from electrical shock. ${ }^{15,16,17,18}$

Peripheral nerve damage associated with third molar extraction is almost exclusively reported in literature as a somatosensory change (primarily involving touch), as inferred from patient reports of paraesthesia. Most of these cases resolved within 6 months of the time of injury. Meanwhile, the studies on chemogustatory changes are minimal or less documented. $2,4,11,13,18,19$ A few reported outcomes of taste tests performed on patients with unilateral chorda tympani or chorda-lingual nerve transection injury collectively demonstrated the permanent alteration of taste sensitivity on the ipsilateral anterior tongue.10,20

The chorda tympani provide gustatory supply for the foremost part of the tongue. The supply for the posterior part is by the glossopharyngeal nerve. Permanent dysesthesias was not noted after raising and retraction of the lingual flaps in impacted tooth which did not undergo day care procedures and was recommended for general anaesthesia. Insertion of Howarth's elevator in order to protect the lingual nerve was noted to have higher incidence of nerve injury.9,11,21,22 Taste chemoreception also depends on the density of the papillae on the tongue and any damage to the chorda tympani nerve causes degeneration of the papillae. These changes are reversible as long as the nerve can regenerate as well. $1,2,6,15,16,20,23$

The study was focused on prospectively determining the incidence and severity of taste changes after surgical removal of mandibular third molar and to establish correlation between difficulty index of impaction and incidence of gustatory changes.

\section{METHODS}

This was a prospective study in which 96 patients who reported to A.B. Shetty Memorial Institute of Dental Sciences, Mangalore from January 2019 to January 2021, and who required lower third molar extraction were included in the study. Their difficulty of impaction was measured using Pell and Gregory difficulty index and their gustatory activity was measured using a spatial taste test and a whole mouth wash test.

The tests were carried out using 5 different stimuli, i.e., sweet, salt, bitter, umami and sour, in different concentrations and the subjects were asked to identify the stimuli preoperatively, postoperatively on day 7 and after 1 month. Tastes were scored from 1 - 9 for decreasing and altered taste sensations.

At $95 \%$ confidence level and $80 \%$ power by assuming 50 $\%$ will have reduced taste, the sample size comes to 96 .

Ethical clearance was attained from the Ethics Committee. Informed consents were made in vernacular languages and attained from all patients before surgical procedure and taste tests. The procedure and possible complications were also explained orally and in their vernacular languages.

\section{Inclusion Criteria}

- Patients in whom mandibular third molar extraction is required on one side.

- Patients without history of recent extractions with respect to same quadrant.

- Patients suffering gustatory changes at the minimum concentration of salt preoperatively.

\section{Exclusion Criteria}

- Patients suffering from xerostomia

- Irradiated patients

- Patients with any tongue disorders like glossitis and depapillation

- Patients suffering from diabetes and hypothyroidism

- Patients in whom middle ear surgery has been done before.

\section{Materials}

Spatial taste test was done using 5 variant chemical stimuli with 3 concentrations

- $\quad$ Sweet - glucose in solutions $0.1 \%, 1 \%, 10 \%$.

- Sour - citric acid in dilutions of $0.1 \%, 1 \%$ and $10 \%$.

- $\quad$ Salty - sodium chloride in dilutions of $0.1 \%, 1 \%, 10 \%$.

- Bitter - solutions of quinine in dilutions $0.001 \%, 0.01 \%$ and $0.1 \%$

- Umami - solutions of monosodium glutamate at $0.1 \%, 1$ $\%$ and $10 \%$

Whole mouth wash taste test was done using 5 variant chemical stimuli that were used in $5 \mathrm{ml}$ samples - 
- $\quad$ Sweet - sucrose $(0.01-1 \mathrm{~mol} / \mathrm{l})$

- Salty - sodium chloride (0.01 - $1.0 \mathrm{~mol} / \mathrm{l})$

- $\quad$ Sour - citric acid (0.32 mmol / l - $0.032 \mathrm{~mol} / \mathrm{l})$

- $\quad$ Bitter - quinine hydrochloride $(0.01-1.0 \mathrm{mmol} / \mathrm{l})$

- Umami - Monosodium glutamate (0.01 - $1.0 \mathrm{mmol} / \mathrm{l})$

- The tongue must be cleaned by distilled water before each sample.

The taste scores will be assessed as -

- Correct

- Incorrect and

- Tasteless

The difficulty index will be assessed using Pell and Gregory classification of impaction. The tooth is classified into position and relation to anterior border of the ramus as follows -

- $\quad$ Class I - sufficient space available between the anterior border of the ramus and the distal side of the second molar for the eruption of the third molar

- $\quad$ Class II - the space available between the anterior border of the ramus and the distal side of the second molar is less than the mesio distal width of the crown of the third molar.

- $\quad$ Class III - the third molar is totally embedded in the bone from the ascending ramus because of absolute lack of space.

Based on depth -

- Position A - highest position of tooth is on level with or above the occlusal line.

- Position B - highest position is below the occlusal plane, but above the cervical level of the second molar.

- Position C - highest position is below the cervical layer of the second molar.

\begin{tabular}{|cc|}
\hline Score & Interpretation \\
1 & Minimum concentration of taste felt (0.1\%) \\
2 & Next concentration of taste felt $(1 \%)$ \\
3 & Maximum concentration of taste felt (10 \%) \\
5 & Altered taste sensation \\
9 & No taste sensation \\
\hline & Table 1. Taste Scoring \\
\hline
\end{tabular}

\section{Statistical Analysis}

- Analysis was done using chi - square test, Multiple ANOVA (MANOVA) and Tukey's test.

- $\quad \mathrm{P}<0.05$ was considered statistically significant.

- $\quad$ SPSS software was used to analyse the collected data.

\section{RESULTS}

In our study, 96 patients underwent third molar surgery, and all patients were evaluated preoperatively, postoperatively on the $7^{\text {th }}$ day and after 1 month. There was only one group of patients and all received the same 5 tastes in 2 forms -

- Spatial taste test (for identification of the taste)

- Whole mouth wash test - for intensity of the taste
The mean age of patients who participated in our study was 25 years with the youngest patient being 17 years old and the oldest patient being 43 years.

Difficulty index scoring using Pell and Gregory classification revealed that 42 patients belonged to the Class I group, 49 to Class II and 5 to the Class III group, out of these, 52 had a position A depth of impaction, 39 had position B and 5 had Position C.

Analysis of our results revealed that with the increased difficulty of impaction there was taste change (P value < 0.05). Most of the patients who participated in our study showed a Class I (43.8 \%) or a Class II relation (51.0\%) with the tooth being in Position A (54.2\%) and Position B (40.6 \%). 5 patients reported with Class III relation and in Position C respectively. There were only 2 patients reported in our study with a Pell and Gregory Classification of Class III Position $\mathrm{C}$ while the rest were either Class III Position A or Position B or Position C with Class II or Class III.

Of the 2 patients that reported in our study were noted to have with Class III Position C, only 1 had unresolved gustatory changes while the other did not show any obvious symptoms. Whereas the patients who reported with Position C showed higher taste changes as compared to those belonging to Class III.

\begin{tabular}{|c|c|c|c|c|c|c|}
\hline Groups $S$ & Sum of Squares & df & \multicolumn{2}{|c|}{ Mean Square } & $\mathbf{F}$ & P Value \\
\hline Umami & 4.000 & 2 & \multicolumn{2}{|c|}{2.000} & .960 & $0.0384^{*}$ \\
\hline Sweet & 5.778 & 2 & \multicolumn{2}{|c|}{2.889} & .454 & $0.035^{*}$ \\
\hline Bitter & 1.896 & 2 & \multicolumn{2}{|c|}{.948} & .135 & $0.04^{*}$ \\
\hline Sour & 4.924 & 2 & \multicolumn{2}{|c|}{2.462} & .295 & $0.045^{*}$ \\
\hline Salt & .694 & 2 & \multicolumn{2}{|c|}{.347} & .171 & $0.043^{*}$ \\
\hline \multicolumn{7}{|c|}{$\begin{array}{c}\text { Intergroup Comparison between Different Time Intervals } \\
\text { of Different Groups of Spatial Taste Test }\end{array}$} \\
\hline \multicolumn{7}{|c|}{${ }^{*} \mathrm{P}$ value $<0.05$ statistically significant } \\
\hline $\begin{array}{l}\text { Dependent } \\
\text { Variable }\end{array}$ & $\begin{array}{l}\text { (I) Time } \\
\text { Intervals }\end{array}$ & \multicolumn{2}{|c|}{$\begin{array}{l}\text { (J) Time } \\
\text { Intervals }\end{array}$} & \multicolumn{2}{|c|}{$\begin{array}{c}\text { Mean } \\
\text { Difference (I-J) }\end{array}$} & P Value \\
\hline Umami & Pre-op & \multicolumn{2}{|c|}{$\begin{array}{l}\text { Post-op } 7 \text { days } \\
\text { Post-op } 1 \text { month }\end{array}$} & \multicolumn{2}{|c|}{$\begin{array}{l}-.25000 \\
-.25000\end{array}$} & $\begin{array}{l}0.044^{*} \\
0.054^{*}\end{array}$ \\
\hline Sweet & Pre-op & $\begin{array}{l}\text { Post-op } \\
\text { Post-op } \\
\text { Post-or }\end{array}$ & $\begin{array}{l}\text { days } \\
\text { nonth } \\
\text { days }\end{array}$ & $\begin{array}{l}-.333 \\
-.250 \\
-.083\end{array}$ & & $\begin{array}{l}0.031^{*} \\
0.01^{*} \\
0.02^{*}\end{array}$ \\
\hline Bitter & Pre-op & \multicolumn{2}{|c|}{$\begin{array}{l}\text { Post-op } 1 \text { month } \\
\text { Post-op } 7 \text { days }\end{array}$} & $\begin{array}{r}. .00 \\
.114 \\
. .083\end{array}$ & & $\begin{array}{c}0.02^{*} \\
0.03^{*} \\
0.014^{*}\end{array}$ \\
\hline Sour & Pre-op & \multicolumn{2}{|c|}{$\begin{array}{l}\text { Post-op } 7 \text { days } \\
\text { Post-op } 1 \text { month }\end{array}$} & $\begin{array}{l}-.031 \\
.260\end{array}$ & $\begin{array}{l}-.08333 \\
-.03125\end{array}$ & $\begin{array}{c}0.001^{*} \\
0.02^{*}\end{array}$ \\
\hline Salt & Pre-op & \multicolumn{2}{|c|}{$\begin{array}{l}\text { Post-op } 7 \text { days } \\
\text { Post-op } 1 \text { month }\end{array}$} & $\begin{array}{l}-.104 \\
-.104\end{array}$ & & $\begin{array}{c}0.03^{*} \\
0.031^{*}\end{array}$ \\
\hline \multicolumn{7}{|c|}{$\begin{array}{c}\text { Pairwise Intergroup Comparison between Different Time } \\
\text { Intervals of Different Groups of Spatial Taste Test }\end{array}$} \\
\hline & & $T a b$ & & & & \\
\hline
\end{tabular}

The intergroup comparison between different time intervals of different groups of spatial taste test was assessed using One-way Analysis of Variance (ANOVA). This comparison showed statistically significant differences ( $P$ value $<0.05$ ) for all the groups.

In our study, Pairwise Intergroup comparison between different time intervals of different groups of spatial taste test was assessed using Post hoc Tukey's test. This comparison showed statistically significant differences (P value $<0.05$ ) from pre-op to post -op 7 days and 1 month for all the groups.

The intergroup comparison between different time intervals of different groups of whole mouth taste test was assessed using One-way Analysis of Variance (ANOVA). This comparison showed statistically significant differences (P 
value $<0.05$ ) for all the groups.

\begin{tabular}{|cccccc|}
\hline Groups & Sum of Squares & df & Mean Square & F & P Value \\
MSG & .250 & 2 & .125 & .956 & $0.038^{*}$ \\
Sucrose & .583 & 2 & .292 & .627 & $0.035^{*}$ \\
Quinine & .132 & 2 & .066 & .144 & $0.016^{*}$ \\
Citric acid & .299 & 2 & .149 & .267 & $0.166^{*}$ \\
NACl & .028 & 2 & .014 & .109 & $0.039^{*}$ \\
\hline Table 3. Intergroup Comparison between Different Time Intervals of \\
Different Groups of Whole Mouth Taste Test \\
\hline${ }^{*}$ P value < 0.05 statistically significant \\
\hline
\end{tabular}

\begin{tabular}{|c|c|c|c|c|}
\hline $\begin{array}{l}\text { Dependent } \\
\text { Variable }\end{array}$ & $\begin{array}{l}\text { (I) Time } \\
\text { Intervals }\end{array}$ & $\begin{array}{l}\text { (J) Time } \\
\text { Intervals }\end{array}$ & $\begin{array}{c}\text { Mean } \\
\text { Difference (I-J) }\end{array}$ & P Value \\
\hline \multirow{2}{*}{ MSG } & \multirow{2}{*}{ Pre-op } & Post-op 7 days & -.06250 & $0.045^{*}$ \\
\hline & & Post-op 1 month & -.06250 & $0.045^{*}$ \\
\hline \multirow{2}{*}{ Sucrose } & \multirow{2}{*}{ Pre-op } & Post-op 7 days & -.10417 & $0.041^{*}$ \\
\hline & & Post-op 1 month & -.08333 & $0.04^{*}$ \\
\hline \multirow{2}{*}{ Quinine } & \multirow{2}{*}{ Pre-op } & Post-op 7 days & .03125 & $0.045^{*}$ \\
\hline & & Post-op 1 month & .05208 & $0.015^{*}$ \\
\hline \multirow{2}{*}{ Citric acid } & \multirow{2}{*}{ Pre-op } & Post-op 7 days & -.01042 & $0.02^{*}$ \\
\hline & & Post-op 1 month & .06250 & $0.032^{*}$ \\
\hline \multirow{2}{*}{$\mathrm{NaCl}$} & \multirow{2}{*}{ Pre-op } & Post-op 7 days & -.02083 & $0.014^{*}$ \\
\hline & & Post-op 1 month & -.02083 & $0.04^{*}$ \\
\hline \multicolumn{5}{|c|}{$\begin{array}{l}\text { Table 4. Pairwise Intergroup Comparison between Different Time } \\
\text { Intervals of Different Groups of Whole Mouth Taste Test }\end{array}$} \\
\hline
\end{tabular}

In our study, Pairwise Intergroup comparison between different time intervals of different groups of whole mouth taste test was assessed using Post hoc Tukey's test. This comparison showed statistically significant differences $(P$ value $<0.05$ ) from pre-op to post -op 7 days and 1 month for all the groups.

\begin{tabular}{|c|c|c|c|c|}
\hline \multirow[b]{2}{*}{ Groups } & \multicolumn{2}{|c|}{ Post-0p 7 Days } & \multicolumn{2}{|c|}{ Post-0p 1 Month } \\
\hline & $\begin{array}{c}\text { Class } \\
\text { P Value }\end{array}$ & $\begin{array}{l}\text { Position } \\
\text { P Value }\end{array}$ & $\begin{array}{c}\text { Class } \\
\text { P Value }\end{array}$ & $\begin{array}{l}\text { Position } \\
\text { P Value }\end{array}$ \\
\hline Umami & 0.001 & 0.000 & 0.000 & 0.001 \\
\hline Sweet & 0.02 & 0.010 & 0.021 & 0.02 \\
\hline Bitter & 0.034 & 0.04 & 0.032 & 0.002 \\
\hline Sour & 0.001 & 0.01 & 0.01 & 0.01 \\
\hline Salt & 0.002 & 0.002 & 0.01 & 0.01 \\
\hline \multicolumn{5}{|c|}{$\begin{array}{c}\text { Table 5. Correlation between Different Groups of Spatial Taste Test } \\
\text { and Pell and Gregory's Classification of Class and Position at Post } \\
\text { Operative } 7 \text { Days and } 1 \text { Month }\end{array}$} \\
\hline
\end{tabular}

In our study, the correlation between different groups of spatial taste test and Pell and Gregory's classification of class and position at postoperative 7 days and 1 month was assessed using Pearson's correlation coefficient. A significant correlation was noted between the groups and difficulty level of impaction. This suggests that with the increased difficulty of disimpaction the level of taste sensation is altered. (P value $<0.05$ )

\begin{tabular}{|ccccc|}
\hline Groups & \multicolumn{2}{c}{ Post-0p 7 Days } & \multicolumn{2}{c|}{ Post-0p 1 Month } \\
Class & $\begin{array}{c}\text { Position } \\
\text { P Value }\end{array}$ & $\begin{array}{c}\text { Class } \\
\text { P Value }\end{array}$ & $\begin{array}{c}\text { P Value } \\
\text { P Value }\end{array}$ \\
Umami & 0.012 & 0.011 & 0.000 & 0.000 \\
Sweet & 0.003 & 0.003 & 0.031 & 0.02 \\
Bitter & 0.03 & 0.02 & 0.04 & 0.002 \\
Sour & 0.000 & 0.000 & 0.002 & 0.000 \\
Salt & 0.012 & 0.002 & 0.01 & 0.01 \\
\hline Table 6. Correlation between Different Groups of Whole \\
Mouth Taste Test and Pell and Gregory's Classification of \\
Class and Position at Post-Operative 7 Days \\
\hline P value < 0.05 statistically significant \\
\hline
\end{tabular}

In our study, the correlation between different groups of whole mouth taste test and Pell and Gregory's classification of class and position at postoperative 7 days and 1 month was assessed using Pearson's correlation coefficient. A significant correlation was noted between the groups and difficulty level of impaction. This suggests that with the increased difficulty of disimpaction the level of taste sensation is altered. (P value $<0.05$ )

\section{DISCUSSION}

Impacted third molar teeth are one of the most frequently occurring problems encountered in a growing adult and its surgical removal is necessary if it becomes a source of problems.4,13 It is also one of the commonest surgeries performed procedures. The difficulty in predicting the associated complications is a triggering challenge and the level of difficulty of impaction has a significant co - relation to nerve injury. 5,24

Nerve injury has been classified as neuropraxia, axonotmesis and neurotmesis from least severe to most severe. Neuropraxia is a result of mild trauma without axonal damage and sensory deficits resolve within days to months. Axonotmesis is a more severe injury in which the nerve sheath is preserved but there is incomplete sensory recovery and afferent fibre degeneration. ${ }^{25}$ Neurotmesis is the most severe injury with nerve severance and no sensory recovery, especially if the nerve is in soft tissue. If the nerve course remains in the bone with the severed pieces in contact, healing may occur. 5,25

Postoperative complications can be caused by surgical technique of disimpaction, angulation of tooth, proximity to nerves and certain patient specific factors. 5,13,26,27 There was a significant correlation between the level of difficulty of impaction which is predicted by the anatomic variables and incidence of postoperative complications such as swelling, trismus, and damage to sensory branches of the fifth nerve focused on the inferior alveolar and lingual nerve, which is one of the most common and accepted risks. This may lead to chemosensory disorders. $6,10,13$

The lingual and retro molar anatomy focuses the surgeon to take into consideration the lingual nerve proximity and it's relation to the third molar region. Injury to the nerve and its close relationship to the chorda tympani results in complications of loss of taste and decreased salivary secretion. $9,13,17,27,28$ There is also loss of sensation in the affected side in the anterior two - third side of the tongue. $14,4,7,7,19,20$ Damage to the chorda tympani nerve also leads to degeneration of the fungiform papillae which reverses as nerve injury heals. ${ }^{2,15,16,23}$ Holzle et al. conducted a study to identify the path of the lingual nerve in the lower third molar region and Karakas et al. confirmed with imaging that in the region of the mandibular third molar that the distolingual crest was about $4.45 \mathrm{~mm}$ and the distance horizontally of the nerve to the cortex lingually was $2.18 \mathrm{~mm}$.

In about $10-15 \%$ of the subjects, the lingual cortical crest was mostly in the distal region of the impacted molar tooth.9,10,24,26,29,30,31 Disimpaction of third molars may have a variable effect on somatosensory and gustatory function due to the microscopic design of the chorda tympani and the lingual nerve. They demonstrated a peculiar organisation in 
relation to the topography of the chorda tympani fibres.1,5,10,13,23 Any injury to the lateral side will cause more injury to the nerve as compared to injury to the medial aspect.

The lingual nerve injury as a result of disimpaction is not predictable. Landis et al. in their study have revealed that there can be a lot of reasons which can lead to damage of the chorda tympani and lead to gustatory changes such as middle ear surgery, and dental procedure is one of them. ${ }^{3,9,10,19,20}$ Although taste changes may infrequently follow the surgical removal of third molars, deficits in somatosensory functions have been documented after surgical extractions. Studies on the gustatory changes have been analysed and shows changes following third molar extraction. ${ }^{4,16,20}$ Analysis of our results revealed that with the increased difficulty of impaction there was taste change ( $\mathrm{P}$ value $<0.05$ ). Most of the patients who participated in our study showed a Class I (43.8\%) or a Class II relation (51.0 \%) with the tooth being in Position A (54.2 $\%)$ and Position B (40.6 \%). 5 patients reported with Class III relation and in Position $C$ respectively. There were only 2 patients reported in our study with a Pell and Gregory Classification of Class III Position C while the rest were either Class III Position A or Position B or Position C with Class II or Class III. Of the 2 patients that reported in our study noted to have with Class III Position C, only 1 had unresolved gustatory changes while the other did not show any obvious symptoms. Whereas the patients who reported with Position C showed higher taste changes as compared to those belonging to Class III.

Similarly, Cheung et al. in their study, highlighted that there is a high risk of lingual nerve deficit with respect to distoangular and vertical impaction. ${ }^{24,27,32,33}$ The chorda tympani nerve injury in our study can be correlated with damage to lingual nerve. This is because of its close anatomical relationship with the third molar.

The possibility of nerve injury is associated with the depth of impacted mandibular molar and its lingual angulation. Valmaseda - Castellon et al. proposed that anatomical variations, such as lingual angulation of the third molar, are related to gustatory changes in relation to disimpaction of third molar. 24,32,33 Modifications in surgery and manoeuvres such as lingual flap retraction and sectioning of tooth vertically, and inexperience of the surgeon, all increase the risk of damage to lingual nerve during the disimpaction of tooth and these are noted to have rare permanent changes. ${ }^{13,32,27,34}$

The CT - lingual nerve traverses to the floor of the oral cavity laterally and is adjacent to the mandibular mesial surface in the area of the third molar. This area is the noted point and high risk of damage occurs during surgical procedures. During administration of local anaesthesia nerve injury can occur. This may be due to direct injury by needle or adverse neurotoxic effects of the anaesthetic compound. ${ }^{17,35}$

Our study revealed that there was a clear indication between the gustatory changes following mandibular TME and the difficulty of the impaction as calculated by Pell and Gregory scoring. Pell and Gregory classification gives a difficulty index which is calculated using the relation of the tooth to the anterior border of ramus and the depth of the impaction of the tooth, but not the angulation of the tooth.

The relationship between the ratings of taste intensity with impaction depth and the passage of time evidence that it was focused on tooth extraction and not associated with the injection of local anaesthetic solution. This resulted in a reduced taste perception. The method of local anaesthesia and its loading dose did not differ for the various depths of impaction. The loss of taste observed at 1 month was not related to impaction depth. This must be due to secondary oedema as a result of nerve compression. Extractions techniques are directly related to longer lasting nerve damage and play a major role along with depth of impaction.

With respect to the stimuli themselves, the Umami flavour and the Salt flavour were felt most frequently and even in the least concentration as well, in both the pre - op groups and the post - op groups. In our study Umami was felt at the minimum concentration by $83.3 \%$ of the patient's pre - op and $77.1 \%$ while $9.4 \%$ were still able to taste in the second most concentration. It has already been inferred by Shankar et al. in their study that salt and bitter stimuli give the best results pre - op and for identification of gustatory changes.

In our study it was also inferred that the Umami flavours are very similar to salty flavour and gives more depth of flavour than salt itself. A similar reaction was reported with quinine in the lowest concentration with $55.2 \%$ responding to the stimuli at minimum concentration and $11.5 \%$ responding to the next concentration.

Whole mouth taste test in our study was used to give us an intensity and identification of the taste itself. Few patients had difficulty in identifying the taste in the operated site to the control site. The whole mouth wash test gave us scores which co - related to the pre - op and post - op identification of the taste itself and hence the inference was correct, incorrect or tasteless depending on the whether they could tell the taste on the operated site. In our study with respect to Monosodium Glutamate, $92 \%$ were able to identify pre - op and $86.5 \%$ post op. This is a slightly higher value than the one achieved from the spatial test and this could be due to the whole tongue being coated by the solution which could have made it more difficult to identify between the control side and the operated side.

In our study we inferred that much like the spatial taste test, the patients who had gustatory changes to the spatial test also had changes to the whole mouth wash test.

Trauma due to disimpaction directly is more likely to cause nerve damage than administration of local anaesthetic injection. ${ }^{17,18,35}$ They reported that their experience to trauma was like feeling an electric shock or pricking of needles. These symptoms resolved completely and there was no residual nerve damage. Also, the inferior alveolar and lingual nerves are between 2 and $3 \mathrm{~mm}$ in diameter and consist of a number of fascicles. This in comparison with the gauge of the needle such as 25 - or 27 local anaesthetic needle which was smaller than $0.5 \mathrm{~mm}$ in external diameter. This was noted when there was a nerve encountered and its tendency to separate the fascicles and pass through them causing minimal damage. Pogrel et al. in their study assessed the damage to the nerves was not due to surgery, but rather due to the administration of the local anaesthetic agent itself.12,17,18 They found it 
difficult how a needle smaller than $0.5 \mathrm{~mm}$ in diameter could cause such profound damage to the complete nerve, since the damage outlined on eleven patients that occupied the complete area of the nerve supply cutaneously was significant. Harn and Durham et al. stated that 200 mandibular blocks could result in seven traumatic episodes (that is, the electric shock sensation), of which one would lead to a post - injection complication. ${ }^{17,36}$

However, the complications in their study was noted for two weeks in 80.77 percent of the post - injection cases which resolved in two weeks. This confirms that even when the patient feels the electric shock, it does not indicate nerve damage. ${ }^{17,36}$ Thus, trauma directly from the needle is not the possible cause of nerve damage. If trauma from needle was involved it would affect only few fascicles that could be damaged.12,17 There may be a neurotoxic effect of the local anaesthetic. Local anaesthetics are noted to be neurotoxic and cause damage. Procaine and tetracaine causes more nerve damage. Among bupivacaine or lidocaine, lidocaine is also noted to be neurotoxic. When injected intrathecally neurotoxicity occurs. . $^{12,17}$

This causes the cauda equina syndrome, or intrafascicularly in greater concentrations. Intrafascicular injections of local anaesthetic could affect the skin or the mucosal region. The sensory parameters supplied by the fasciculi and not focused to the whole nerve.12,17,36 The results of our study impresses that the difficulty of impaction is directly related to sensory deficits of taste and somatosensory reception. The standard local anaesthetic syringe used clinically, has too small a diameter and does not cause any permanent or even long-lasting damage to the chorda tympani or lingual nerves.

Our study successfully co - relates the surgical technique involved in disimpaction of the mandibular third molar and thus related to the gustatory changes associated with it.

\section{CONCLUSIONS}

- There is an association between the difficulty of impaction and suprathreshold gustatory changes following TME.

- There is a higher incidence of gustatory changes with respect to Class III and Position C classification of Pell and Gregory Index following surgical extraction.

\section{Limitations}

1. This a single-centre study, and the results cannot be generalized for the general population.

2. Pell and Gregory classification does not give us the angulation of the tooth and hence, better classification can be used for evaluation of the tooth.

Data sharing statement provided by the authors is available with the full text of this article at jemds.com.

Financial or other competing interests: None.

Disclosure forms provided by the authors are available with the full text of this article at jemds.com.

\section{REFERENCES}

[1] Witt M. Anatomy and development of the human taste system. Handb Clin Neurol 2019;149:147-71.

[2] Hummel T, Welge-Lüssen A. Taste and smell: an update. Vol. 63. Basel, New York: Karger, Cop 2006.

[3] Landis BN, Lacroix J. Postoperative / posttraumatic gustatory dysfunction. In: Hummel T, Welge-Lüssen A, eds. Taste and smell. Vol. 63. Basel: Karger Publishers 2006:242-54.

[4] Anand R, Shankar DP, Manodh P, et al. Short-term evaluation of gustatory changes after surgical removal of mandibular third molar- a prospective randomized control trial. J Oral Maxillofac Surg 2018;76(2):258-66.

[5] Lewis D, Dandy WE. The course of the nerve fibers transmitting sensation of taste. Archives of Surgery 1930;21(2):249-88.

[6] Shafer DM, Frank ME, Gent JF, et al. Gustatory function after third molar extraction. Oral Surg Oral Med Oral Pathol Oral Radiol Endod 1999;87(4):419-28.

[7] Wofford DT, Miller RI. Prospective study of dysesthesia following odontectomy of impacted mandibular third molars. Journal of Oral and Maxillofacial Surgery 1987;45(1):15-9.

[8] Shad S, Shah SM, Alamgir A, et al. Frequency of lingual nerve injury in mandibular third molar extraction: a comparison of two surgical techniques. J Ayub Med Coll Abbottabad 2015;27(3):580-3.

[9] Blackburn CW, Bramley PA. Lingual nerve damage associated with the removal of lower third molars. $\mathrm{Br}$ Dent J 1989;167(3):103-7.

[10] Nickel AA Jr. A retrospective study of paresthesia of the dental alveolar nerves. Anesth Prog 1990;37(1):42-5.

[11] Lata J, Tiwari AK. Incidence of lingual nerve paraesthesia following mandibular third molar surgery. Natl J Maxillofac Surg 2011;2(2):137-40.

[12] Pogrel MA, Bryan J, Regezi J. Nerve damage associated with inferior alveolar nerve blocks. J Am Dent Assoc 1995;126(8):1150-5.

[13] Renton T, McGurk M. Evaluation of factors predictive of lingual nerve injury in third molar surgery. Br J Oral Maxillofac Surg 2001;39(6):423-8.

[14] Kiesselbach JE, Chamberlain JG. Clinical and anatomic observations on the relationship of the lingual nerve to the mandibular third molar region. J Oral Maxillofac Surg 1984;42(9):565-7.

[15] Cheal M, Oakley B. Regeneration of fungiform taste buds: temporal and spatial characteristics. J Comp Neurol 1977;172(4):609-25.

[16] Cheung LK, Leung YY, Chow LK, et al. Incidence of neurosensory deficits and recovery after lower third molar surgery: a prospective clinical study of 4338 cases. Int J Oral Maxillofac Surg 2010;39(4):320-6.

[17] Krafft TC, Hickel R. Clinical investigation into the incidence of direct damage to the lingual nerve caused by local anaesthesia. J Craniomaxillofac Surg 1994;22(5):294-6.

[18] Smith MH, Lung KE. Nerve injuries after dental injection: a review of the literature. J Can Dent Assoc 2006;72(6):559-64. 
[19] Zhang Y, Hoon MA, Chandrashekar J, et al. Coding of sweet, bitter and umami tastes: different receptor cells sharing similar signaling pathways. Cell 2003;112(3):293-301.

[20] Ridaura-Ruiz L, Figueiredo R, Valmaseda-Castellón E, et al. Sensibility and taste alterations after impacted lower third molar extractions. A prospective cohort study. Med Oral Patol Oral Cir Bucal 2012;17(5):e759-64.

[21] Chiapasco M, De Cicco L, Marrone G. Side effects and complications associated with third molar surgery. Oral Surg Oral Med Oral Pathol 1993;76(4):412-20.

[22] Robinson PP, Smith KG. Lingual nerve damage during lower third molar removal: a comparison of two surgical methods. Br Dent J 1996;180(12):456-61.

[23] Zuniga JR, Chen N, Miller IJ Jr. Effects of chorda-lingual nerve injury and repair on human taste. Chem Senses 1994;19(6):657-65.

[24] Voegelin TC, Suter VGA, Bornstein MM. Complications during and after surgical removal of mandibular third molars. Impact of patient related and anatomical factors. Schweizer Monatsschr Zahnmed 2008;118(3):192-8.

[25] Seddon HJ. Three types of nerve injury. Brain 1943;66(4):237-88.

[26] Graff-Radford SB, Evans RW. Lingual nerve injury. Headache: The Journal of Head and Face Pain 2003;43(9):975-83.

[27] Rood JP. Permanent damage to inferior alveolar and lingual nerves during the removal of impacted mandibular third molars. Comparison of two methods of bone removal. Br Dent J 1992;172(3):108-10.

[28] Miloro M, Halkias LE, Slone HW, et al. Assessment of the lingual nerve in the third molar region using magnetic resonance imaging. J Oral Maxillofac Surg 1997;55(2):134-7.

[29] Hölzle FW, Wolff KD. Anatomic position of the lingual nerve in the mandibular third molar region with special consideration of an atrophied mandibular crest: an anatomical study. Int $\mathrm{J}$ Oral Maxillofac Surg 2001;30(4):333-8.

[30] Karakas P, Üzel M, Koebke J. The relationship of the lingual nerve to the third molar region using radiographic imaging. Br Dent J 2007;203(1):29-31.

[31] Tojyo I, Nakanishi T, Shintani Y, et al. Risk of lingual nerve injuries in removal of mandibular third molars: a retrospective case-control study. Maxillofac Plast Reconstr Surg 2019;41(1):40.

[32] Pell GJ, Gregory GT. Report on a ten-year study of a tooth division technique for the removal of impacted teeth. American Journal of Orthodontics and Oral Surgery 1942;28(11):B660-6.

[33] Valmaseda-Castellón E, Berini-Aytés L, Gay-Escoda C. Lingual nerve damage after third lower molar surgical extraction. Oral Surg Oral Med Oral Pathol Oral Radiol Endod 2000;90(5):567-73.

[34] Bataineh AB. Sensory nerve impairment following mandibular third molar surgery. J Oral Maxillofac Surg 2001;59(9):1012-7.

[35] Haas DA, Lennon D. A 21 year retrospective study of reports of paresthesia following local anesthetic administration. J Can Dent Assoc 1995;61(4):319-20.

[36] Harn SD, Durham TM. Incidence of lingual nerve trauma and postinjection complications in conventional mandibular block anesthesia. J Am Dent Assoc 1990;121(4):519-23. 